rivers in terms of the dependent variables of channel type, depth, flow strength and slope.

The profiles of rivers existing today are known to be strongly related to the nature of the sediment load that the rivers carry. Rivers carrying a bed load have braided, almost straight, channels and are some sixty times as wide as they are deep, whereas rivers carrying a suspended load or a mixed load have channels which meander and have a smaller ratio of width to depth (about ten). The depth of a river channel is given by the thickness of an individual graded sand cycle which is deposited by the river in a single unit during flood conditions. Thus Friend and Moody-Stuart were able to recognize two distinct river systems. An eastern one was characterized by bedload braided channels, averaging, at the high stage, at least 2 to $3 \mathrm{~m}$ in depth, 120 to $170 \mathrm{~m}$ in width, and low sinuosity. The regional slope was gentle $\left(15 \mathrm{~cm} \mathrm{~km}^{-1}\right)$ and towards the northnorth-west. The western system was a complete contrast, having channels with flood depths of about $0.7 \mathrm{~m}$ of mixed or suspended-load type. They were highly sinuous, and about $7 \mathrm{~m}$ wide, depositing sediment on a relatively steep slope $\left(100 \mathrm{~cm} \mathrm{~km}^{-1}\right)$, which faced east-north-east, and extending from a source only a short distance away.

From these values pertinent to the two river systems the authors calculated the mean annual discharge from each and hence the relative size of the source areas; the eastern source area turned out to be about 400 times greater than the western one. From this information they plotted the source areas and obtained approximate limits on the relief from a knowledge of the total volume of the Wood Bay Formation derived by denudation from these source areas. Thus the eastern area occupied an area of some $10,000 \mathrm{~km}^{2}$ extending some $200 \mathrm{~km}$ south-east of the present alluvial area and with a relief of $\sim 6,000 \mathrm{~m}$, whereas the much smaller western source area was $\sim 25 \mathrm{~km}^{2}$ with a relief of $\sim 150 \mathrm{~m}$.

The full significance of this reconstruction is not apparent until one realizes that the obvious source area for the Wood Bay Formation is the denuded Caledonian mountain system of $\mathrm{Ny}$ Friesland, situated immediately to the east of the Wood Bay Formation outcrop and separated from it by the north-south Balliolbreen Fault. These mountains have had at least 10 $\mathrm{km}$ of Heckla Hoek sediments and metasediments eroded from them, and orthoclase and heavy mineral detritus within the Wood Bay Formation is similar to that in the Heckla Hoek. Friend and Moody-Stuart suggest that sinistral late Devonian (Svalbardian) movement along the Balliolbreen Fault carried
Ny Friesland from a source position $200 \mathrm{~km}$ south-south-east of the Wood Bay Formation to its present position. This is in accord with earlier suggestions by Harland (Phil. Trans. Roy. Soc. Lond., 258 ; 1965) that late Devonian sinistral transcurrent movement affected the whole North Atlantic area.

\section{PHYSICAL METALLURGY}

\section{EM in extremis}

from our Materials Science Correspondent

IN 1938 two crystallographers, Guinier in Paris and Preston in London, independently found smudges on their X-ray Laue photographs prepared from agehardened duralumin crystals, and independently postulated that the smudges were caused by thin plates, or "zones", of copper trying to precipitate out of solution in aluminium. (Nature, as so often, was in at the birth $(142,569,570$; 1938).) Thereupon Preston moved on to other interests (see his obituary in Nature recently $(238,362 ; 1972)$ ) and it was left to Guinier to spend many years of painstaking X-ray diffraction piecing together the structural details of the formations which have ever since been known as Guinier-Preston zones-GP zones for short. X-ray diffraction, however beautifully used, is a somewhat inadequate instrument when one has to analyse a population of zones which differ in all their dimensions and even in their fine structure, and so the advent of thin-film electron microscopy in the 1950s brought about a revival of interest in GP zones: the hope was to observe them directly.

The difficulty was that the zones in their early stages were known to be ultra-thin, possibly only one atomic diameter thick, and this was quite beyond the resolving power of the

\section{Radio Emission from Nebulae Around Stars}

IN next Monday's Nature Physical Science (April 9) Hjellming, Blankenship and Balick report the detection of radio emission associated with the stars MWC 349 and RY Scuti. This confirms earlier observations of the sources at several radiofrequencies, and provides evidence that the radio emission comes from resolvable radio "nebulosities" with thermal radio spectra.

The observations now reported were made at 2,695 and $8,085 \mathrm{MHz}$ with the NRAO interferometer. Neither source showed any signs of variability at these frequencies during the period of observation (October 1972 to February 1973 for MWC 349 ; February 19 to 28, 1973 for RY Scuti), both have the same kind of visibility function, and both were nearly unresolved at $2,695 \mathrm{MHz}$ with the longest interferometer spacing microscopes of 10 to 15 years ago. The zones are, however, surrounded by a field of elastic strain: this field is both the source of the hardening associated with the presence of the zones and the means by which it is possible to see the zones in an electron microscope. The strained aluminium lattice diffracts electrons either more or less efficiently than the unstrained lattice, and thus the photographs image the strain fields rather than the zones themselves-the smile instead of the Cheshire cat. The trouble was that a picture of the smile failed to carry any information about the Cheshire cat's teeth.

Now at last it is possible to see the zones themselves and thus to measure their length and thickness accurately. Two recent papers (Phillips, Acta Metallurgica, 21, 219; 1973; and Phillips and Tanner, ibid., 21, 441; 1973) reproduce electron micrographs of GP zones at unprecedented resolution. The first report is concerned with $\mathrm{Al}-\mathrm{Cu}$, the second with a closely related alloy, $\mathrm{Cu}-\mathrm{Be}$. In each instance, (002) lattice planes of the matrix are imaged as sharp fringes at a spacing of about $2 \AA$; at an early stage of ageing, GP zones of monatomic thickness are revealed as disturbances of these fringes. In $\mathrm{Cu}-\mathrm{Be}$, the zones are shown up by local brightness reversal of the lattice fringes, whereas in $\mathrm{Al}-\mathrm{Cu}$, Phillips actually succeeded in demonstrating a localized reduction in lattice spacing near the zones, the direct expression of the associated strain field. This is a remarkable technical achievement in electron microscopy, and opens the way to a more exact interpretation of the early stages of age hardening; a start has already been made by using the observations to identify the zone dimensions corresponding to the rnaximum in electrical resistivity during the ageing of a $\mathrm{Cu}-\mathrm{Be}$ alloy.

$(2,700 \mathrm{~m})$; this suggests sizes $\lesssim 3$ arc s. There is also an indication of complex structure in both sources.

So it seems that the radio emission is definitely not coming from a point source in either case. The emission comes instead from compact regions surrounding each star, and Hjellming et al. point out that it would be incorrect to call these objects "radio stars" because they do not show the strong variability, indicating "an intimate relationship" with the underlying star, that the name has come to imply. These two sources have, in fact, some similarities to planetary nebulae with electron temperatures around $10^{4}$ $\mathrm{K}$, dominant emission measures of $\sim 10^{8} \mathrm{pc} \mathrm{cm}^{-6}$, and in general similar properties to such well-known planetary nebulae as NGC 7027. 